\title{
PERENCANAAN CHECKDAM KALI NGASINAN KANAN DESA NOTOREJO KECAMATAN GONDANG KABUPATEN TULUNGAGUNG
}

\author{
Ahmad Nashirudin $^{1 *}$, Sigit Winarto ${ }^{2}$, Sudjati ${ }^{3}$ \\ ${ }^{1 *}$ Fakultas Teknik Sipil Universitas Kadiri \\ e-mail : ${ }^{1}$ ahmad.nashirudin@gmail.com ${ }^{2}$ sigit.winarto@unik-kediri.ac.id,${ }^{3}$ sudjati@unik- \\ kediri.ac.id
}

\begin{abstract}
Checkdam is a controlling building created because of the flow of water with a large enough sediment concentration, where the sediment comes from soil erosion in the upstream part of the river, to find out the analysis of hydrology, regarding its rainfall, analyze the flood discharge. With the form of a checkpoint in the village of Notorejo, it can prevent and reduce disasters due to the flow of sediments that are formulated in such a way that the river concerned can function normally and effectively in terms of two angles, namely flood control and river development. Rainfall based on calculation of log pearson type III on R20 is 100mm, and Flood Debit Plan $167 \mathrm{~m} 3 /$ dt. The ability of the sediment capacity of $700,692 \mathrm{~m} 3 / \mathrm{dt}$ and the capacity of sediment capacity to remain 525,519. and able to withstand shear force and rolling stability, this discharge plan is useful for reducing sediment that enters the river salts and provides safety of surrounding agricultural areas due to erosion, stabilizes the riverbed, directs river flow and reduces the occurrence of breakdowns in bridge structures along the river flow mate.
\end{abstract}

Keywords : Checkdam, Hydrology, Sediment, Flood Discharge, Stability.

\begin{abstract}
Abstrak
Checkdam adalah bangunan pengendali yang dibuat karena adanya aliran air dengan konsentrasi sediment yang cukup besar, dimana sedimen tersebut berasal dari erosi tanah pada bagian hulu sungai, Untuk mengetahui tinjauan analisa hidroliginya, mengenai curah hujannya, analisa debit banjirnya. Dengan di bentuknya cekdam di desa notorejo dapat mencegah dan mengurangi bencana akibat aliran sedimen yang dirumuskan sedemikian rupa sehingga sungai yang bersangkutan dapat berfungsi normal dan efektif di tinjau dari dua sudut yaitu pengendalian banjir dan pengembangan sungai. Curah hujan berdasarkan perhitungan log pearson type III pada R20 adalah $100 \mathrm{~mm}$, dan Debit Banjir Rencana $167 \mathrm{~m}^{3} / \mathrm{dt}$. Kemampuan daya tampung sedimen $700.692 \mathrm{~m}^{3} / \mathrm{dt}$ dan kemampuan daya tampung sedimen tetap 525.519. dan mampu menahan stabilitas gaya geser dan guling,debit rencana ini bermanfaat untuk mengurangi sedimen yang masuk ke checkdam kali ngasinan dan memberikan pengamanan daerah pertanian di sekitar akibat erosi, menstabilkan dasar sungai, mengarahkan aliran sungai dan mengurangi timbulnya kerobohan pada struktur jembatan di sepanjang aliran sungai ngasinan.
\end{abstract}

Kata Kunci : Cekdam, Hidrologi, Sediment, Debit Banjir, Stabilitas. 


\section{PENDAHULUAN}

Standar untuk perhitungan dalam perencanaan checkdam yang menyangkut perencanaan bangunan bendung perlu dilakukan tinjauan khusus[1][2]. Checkdam adalah bangunan pengendali sebuah sungai yang dibuat karena adanya aliran air dengan konsentrasi sediment yang cukup besar, dimana sedimen tersebut berasal dari erosi tanah pada hulu sungai. dalam perencanaan checkdam adalah sejauh mana sediment yang larut mampu ditahan oleh bangunan ini[3][4]. Prinsip stabilitas bangunan checkdam terhadap gaya guling, gaya geser, yang ada pada bangunan untuk mencegah kerusakan yang di karenakan aliran air dan sediment sangat penting. Pemilihan lokasi check dam harus tepat arena daya dukung tanah sangat berperan penting dalam bangunan checkdam[5][6]. Pertimbangan lain dengan adanya perencanaan check dam ini adalah jika di pandang dari segi ekonomis biaya pembngunan, perawatan tidak terlalu mahal dan dari segi keamanan artinya aman untuk konstruksi itu sendiri yaitu bangunan mampu menahan aliran sediment. Erosi dan sedimentasi merupakan dua buah masalah yang saling berkaitan[7].

Erosi tanah yang meliputi proses pelepasan butiran-butiran tanah dan proses pemindahan tanah yang menyebabkan timbulnya bahan endapan atau sedimentasi ditempat lain. Pada saat permulaan turun hujan, atunya air hujan merupakan penghasil utama butiran-butiran tanah/sedimen yang lepas dalam proses erosi tanah[8]. Bersama dengan aliran air tersebut, butiran-butiran tanah yang lepas akibat proses erosi dapat terangkat masuk kedalam aliran sungai dan kemudian dapat diendapan pada tempat-tempat tertentu berupa endapan maupun sedimentasi. Endapan sedimentasi tersebut apa bila semakin lama akan semakin banyak jumlahnya, maka dapat menimbulkan pendangkalan pada waduk dan muara sungai yang dapat mengakibatkan berkurangnya umur pada rencana waduk[9]. Banyaknya angkutan bahan endapan tersebut tergantung dari besarnya erosi tanah yang terjadi. Semakin banyak jumlah suatu sedimen yang terangkut itu akan menunjukan semakin besar tingkat erosi tanah yang terjadi dalam aliran sungai yang bersangkutan. Karena erosi dan sedimentasi merupakan suatu hal yang saling berkaitan, maka dibawah ini akan di bahas masalah-masalah tersebut[10].

\section{METODOLOGI PENELITIAN}

\subsection{Tinjauan Pustaka Dan Dasar Teori}

Setiap proyek konstruksi memiliki rencana jadwal kegiatan dan rencana pembiayaan proyek yang dibuat pada saat proses pekerjaan di lapangan berjalan. tujuan dari pembuatan rencana biaya dan jadwal kegiatan tersebut adalah agar proyek dapat dilaksanakan sesuai dengan acuan yang direncanakan oleh kontraktor[11]. Namun pada pelaksanaannya, sering terjadi perbedaan antara jadwal kegiatan dengan realisasi yang terjadi di lapangan. Pelaksanaan yang tidak sesuai dengan jadwal dapat mengakibatkan keterlambatan yang dapat menyebabkan 
perubahan pada biaya proyek[12]. Menurut sebuah survey yang di lakukan oleh Mehzer et al,1998 mengenai faktor penyebab lambatnya/keterlambatan proyek konstruksi.

Kontraktor dan perusahaan konsultan/ arsitektur menemukan bahwa owner lebih berfokus pada soal keuangan sedangakan kontraktor dengan permasalahan kesepakatan kontrak dan konsultan menjadikan manajemen proyek sebagai persoalan yang sagat penting[13].

\subsection{Dasar Teori}

\subsubsection{Analisa Hidrologi}

Curah Hujan

Perhitungan debit banjir rencana ini didasarkan pada data pengamatan air hujan Stasiun Pagerwojo yang mana stasiun tersebut merupakan stasiun pengamatan hujan yang paling dekat dengan cheacthman area yang ditinjau di atas lokasi bangunan checkdam[14].

\subsubsection{Analisa Perhitungan Besar Curah Hujan}

A. Metode Gumbel

Dan harga (Yt) dengan periode ulang 20 tahun dapat dihitung dengan rumus

$$
Y t=-\operatorname{In}(\operatorname{In}(T / T-1)) \ldots \ldots \ldots \ldots . . .1
$$

Kemudian faktor $\mathrm{K}$ untuk harga yang ekstrim distribusi gumbel dinyatakan dalam persamaan, dimana harga reduced mean (Yn) dan harga reduced standar deviation (Sn) disesuaikan dengan tabel[15].

$$
K=\frac{Y t-Y n}{S n} \ldots \ldots 2
$$

\section{B. Metode Log Pearson Type III}

Perhitungan besarnya curah hujan rancangan ditinjau dari nilai Cs (Koefisien Kepencengan) dan Ck (Koefisien Kepuncakan). Persamaan Cs dan Ck adalah :

$$
\begin{gathered}
C s=\frac{\sum_{i=1}^{n} n(\log x 1-\log x 2)}{(n-1)(n-2) S_{d}^{3}} \\
C k=\frac{\sum_{i=1}^{n} n(\log x i-\log x i)}{(n-1)(n-2) S_{d}^{4}}
\end{gathered}
$$

Secara besar langkah-langkah perhitungan metode Log Pearson Type III adalah sebagai berikut:

1. Mengubah data hujan $X_{1}, X_{2} \ldots \ldots \ldots \ldots . . . X_{n}$ menjadi $\log X_{1}, \log X_{2}$ $\log X_{n}$

2. Menghitung hargarata-ratanya.

3. Mengukur standart deviasi dengan persamaan berikut ini :

$$
S d=\sqrt{\sum_{i=0}^{n} \frac{(\log x i-\log x)}{(n-1)}} \ldots \ldots . . . .4
$$

4. Menghitung koefisien kepencengan dengan persamaan berikut ini : 


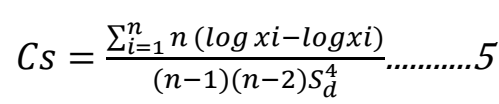

5. Menghitung nilai logaritma debit dengan waktu balik yang dikehendaki dengan rumus[16]:

$$
C S=\frac{\sum_{i=1}^{n} n(\log x i-\log x i)}{(n-1)(n-2) S_{d}^{4}}
$$

6. Harga $\mathrm{G}$ bisa dilihat dari tabel untuk harga $\mathrm{C}$, yang sesuai.

7. Dicari antilog dari log Q agar mendapatkan debit banjir untuk balok QT.

8. Perhitungan disribusi besar curah hujan rancangan metode Log Pearson Type III disajikan dalam bentuk tabel untuk masing-masing DAS yang ditinjau didasarkan pada PSA-007 (Pedoman Study Pengairan) Guideline for Dam Floord Safety, sehingga persamaan curah hujan rancangan adalah sebagai berikut:

$$
\text { Rrancangan } \quad=\text { Rmax } X_{X} A F_{X} \text { Faktor Reduksi.....7 }
$$

\subsubsection{Analisa Debit Banjir Rencana}

Metode Rasional

Dengan metode rasional bahwa rumusan debit $\max ($ maksimum) dapat dihitung menggunakan rumus[17]:

$$
Q=0.278 \text { C.I.A.................... }
$$

Harga intensitas hujan rata-rata selama waktu tiba dari banjir dapat dihitung dengan metode Monobe persamaan [18]:

$$
I=\frac{R_{24}}{24}\left(\frac{24}{t}\right) \ldots \ldots \ldots \ldots \ldots
$$

Sehigga :

$$
t=\frac{L}{V}, \operatorname{dan} V=72\left(\frac{H}{L}\right)
$$

\subsubsection{Perencanaan Dimensi Checkdam}

A. Pemilihan Type Checkdam

Beberapa type bangunan dam secara umum dibedakan menjadi beberapa type antara lain :

1. Type Gravitasi

2. Type Arch (Dam Lengkung)

3. Type Rock Fill Dam (Dam dibuat dari timbunan batu lepas)[19]

Sedangkan bangunan checkdam yang direncanakan dibuat dengan menggunakan bahan dari beton/pasangan batu kali dibedakan menjadi dua type saja yaitu:

1. Type Gravitasi

2. Type Arch. 
Dengan melihat kondisi lokasi penelitian yang mana bangunan check dam dibangun pada lokasi di bagian hulu sungai yang memiliki kemiringan yang cukup curam, maka kriterian yang sangat menentukan diantara kedua type bendung sesuai dengan usaha pengendalian sedimen adalah berdasarkan tinggi efektif (tinggi tampungan) dari bending yang direncanakan. Adapun kriteria tersebut adalah sebagai berikut[20] :

1. Tinggi Efektif $(\mathrm{H}) \leq 15 \mathrm{~m}$ dipakai type grafitasi.

2. Tinggi Efektif $(\mathrm{H}) \geq 15 \mathrm{~m}$ dipakai type arch.

B. Perencanaan Dimensi Checkdam

Perencanaan dimensi bendung sangat tergantung dari beberapa hal, antara lain sebagai berikut :

1. Fungsi bangunan bendung yang direncanakan.

2. Tinggi rencana banjir[21].

3. Kemiringan dasar sungai rencana.

4. Kondisi geologi lokasi calon bendung yang dibangun[22].

\subsection{Kontrol Stabilitas Checkdam}

Kondisi aliran dapat diperkirakan dengan hitungan sebagai berikut:

Debit aliaran tiap meter panjang

$$
\begin{aligned}
& (\mathrm{Qo})=\frac{Q o}{b} \ldots \ldots \ldots \ldots \ldots . . .10 \\
& (\mathrm{Vo})=\frac{q o}{h} \ldots \ldots \ldots \ldots . . .11
\end{aligned}
$$

Kecepatan aliran diatas mercu dam

Panjang terjunan $(\ell \mathrm{w})$ dapat dihitung dengan rumus :

$$
\begin{aligned}
& L w=V_{0}\left(\frac{2(H 1+0.5 h}{\mathrm{g}}\right) \ldots \\
& \mathrm{g}=9.8 \mathrm{~m} / \mathrm{dt}^{2}
\end{aligned}
$$

Kecepatan air untuk terjunan (V1) dihitung menggunakan rumus :

$$
\begin{aligned}
& \mathrm{V} 1=\sqrt{2 g\left(H_{1}+h\right.} \ldots \ldots \ldots \ldots \ldots . .13 \\
& (\mathrm{~h} 1)=\frac{q_{1}}{V_{1}} \ldots \ldots \ldots \ldots \ldots . .14
\end{aligned}
$$

Tinggi air di titik jatuhnya terjunan

A. Gaya-gaya Yang Bekerja

Dalam menghitung stabilitas check dam, diperlukan perhitungan gaya yang bekerja sesuai dengan tinggi dam maupun keadaan air yang mengalir. 
Tabel 1. Gaya -gaya yang bekerja

\begin{tabular}{|c|l|cl|}
\hline Tinggi Dam & Muka Air Normal & \multicolumn{2}{c|}{ Muka Air Banjir } \\
\hline \multirow{2}{*}{$\mathrm{H} \leq 15 \mathrm{~m}$} & & $3.1 .1 \quad$ Berat Sendiri \\
& & $3.1 .2 \quad$ Tekanan air statis \\
\hline & 3.1 .3 Berat Sendiri & 3.1 .9 Berat Sendiri \\
& 3.1 .4 Tekanan Hidrostatis & 3.1 .10 Tekanan Hidrostatis \\
$\mathrm{H} \geq 15 \mathrm{~m}$ & 3.1 .5 Tekanan Sedimen & 3.1 .11 Tekanan Sedimen \\
& 3.1 .6 Tekanan Keatas \\
& 3.1 .7 Tekanan Hidrodinamis & 3.1 .12 Tekanan Keatas \\
& 3.1 .8 Gaya Gempa & & \\
\hline
\end{tabular}

Sumber : Volcanic Sabo Technical Center "Desaign Sabo"

1. Perhitungan Berat Sendiri Dam

Perhitungan berat volume dam dapat dihitung dengan menggunakan rumus:

$$
\mathrm{W}=\gamma_{C} \cdot A \ldots \ldots \ldots \ldots \ldots . . .15
$$

2. Gaya Tekan Statis

Tekanan air statis ini mempengaruhi besar gaya tekan air dengan rumus sebagai berikut:

$$
\mathrm{P}=\mathrm{Y}_{\mathrm{W}} \cdot \mathrm{H}_{\mathrm{W}}
$$

3. Gaya Tekan Sedimen

Tekanan sedimen mempengaruhi besar gaya tekan sedimen terhadap check dam, dengan rumus sebagai berikut :

$$
P_{e v}=Y_{s i .} h e
$$

B. Kontrol Stabilitas Terhadap Guling

Kestabilan terhadap guling diperiksa berdasarkan kedudukan kerja gaya resultan yang ditmbulkan oleh beban yang bekerja. diukur dari kedua sisinya dengan rumus :

$$
X=\frac{\sum(M x-M y)}{\sum V} \ldots \ldots \ldots \ldots . . . .18
$$

Syarat posisi $\mathrm{x}$ adalah :

$$
1 / 3 b_{2} \leq x \leq 2 / 3 b_{2} \ldots \ldots .19
$$

C. Kontrol Stabilitas Terhadap Geser

Tubuh dam harus tidak bergeser oleh gaya-gaya yang bekerja. sudut geser dalam dari tanah dasar dam dengan rumus:

$$
\frac{\sum V}{\sum H} \mathrm{f} \geq S f \ldots \ldots \ldots . . .20
$$

D. Kontrol Stabilitas Terhadap Pondasi besarnya tegangan yang terjadi di bawah pondasi dapat dihitung dengan rumus :

$$
\sigma_{1,2}=\frac{\Sigma V}{\Sigma F}\left(1 \pm \frac{6 e}{b}\right) \ldots . .21
$$


E. Kontrol Tebal Lantai Apron Terhadap Gaya Up Lift

Besarnya tekan up lift dapat dicari dengan rumus:

$$
U x=\mu . \Delta h\left(1-\frac{X}{\Sigma L}\right) \gamma_{w} \ldots . .22
$$

\subsection{Estimasi Daya Tampung Sedimen}

Daerah dibatasi oleh $\mathrm{I}_{\mathrm{o}}$ dan $\mathrm{I}_{\mathrm{d}}$. Besar kemiringan $\mathrm{I}_{\mathrm{s}}$ dan $\mathrm{I}_{\mathrm{d}}$ adalah sebagai berikut :

$$
\begin{aligned}
& I_{s}=(3 / 4 \sim 2 / 3) . I_{0} \ldots \ldots \ldots \ldots \ldots \ldots \ldots . . .23 \\
& I_{d}=1 / 2 \text {. Io..............................24 }
\end{aligned}
$$

Dimana besarnya estimasi ditentukan dengan rumus berikut:

$$
V=\frac{1}{2} \frac{B \cdot H^{2}}{I o-I r}
$$

Dalam penelitian ini kategori jenis penelitian survei yaitu penelitian dengan pengamatan lagsung oleh peneliti kepada suatu objek. Metode penelitian adalah suatu ilmu untuk mempelajari cara-cara penelitian untuk menemukan, mengumpulkan, mengembangkan, menganlisis dan menguji kebenarannya, dikerjakan dengan hati-hati, sistematis dan berdasarkan ilmu dan pengetahuan dengan metode ilmiah. Untuk peneltian ini pengumpulan data dilakukan menggunakan cara mengumpulkan data primer dan data skunder.

\subsection{Objek Penelitian}

Objek penelitian adalah kajian perencanaan checkdam kali Ngasinan Desa Notorejo Kecamatan Gondang Kabupaten Tulungagung.

\subsection{Teknik Pengumpulan Data}

1. Studi Literatur

2. Perencanaan dan pengumpulan data sekunder maupun primer

3. Analisa Perencanaan

\section{ANALISA DAN PEMBAHASAN}

Perhitungan debit banjir rencana sebagai dasar penentuan dimensi dam yang akan dibuat dan dihitung berdasarkan curah hujan rata-rata pada stasiun pencatat hujan yang kini Stasiun Wonorejo dan Stasiun Pagerwojo yang mana letak kedua stasiun tersebut berada di dalam chatctment Area Kali Ngasinan. Sedang luas Cathcment Area Kali Ngasinan sendiri menurut data adalah $\pm 29.8 \mathrm{~km} 2$.

\subsection{Analisa Perhitungan Besar Curah Hujan}

3.1.1 Metode Gumbel 
Dari data curah hujan rata-rata pada stasiun yang ada kemungkinan disusun menurut rangking.

Tabel 2. Metode Gumbel dalam periode ulang 20 Tahun

\begin{tabular}{|c|c|c|c|c|}
\hline No & $\mathrm{x}(\mathrm{mm})$ & $\mathrm{T}=(\mathrm{n}+1) / \mathrm{m}$ & $(\mathrm{x}-\bar{x})$ & $(\mathrm{x}-\bar{x})^{2}$ \\
\hline 1 & 152,00 & 153,00 & 60,10 & $3.612,01$ \\
\hline 2 & 116,50 & 58,75 & 24,60 & 605,16 \\
\hline 3 & 101,50 & 34,17 & 9,60 & 92,16 \\
\hline 4 & 101,00 & 25,50 & 9,10 & 82,81 \\
\hline 5 & 96,50 & 19,50 & 4,60 & 21,16 \\
\hline 6 & 92,00 & 15,50 & 0,10 & 0,01 \\
\hline 7 & 92,00 & 13,29 & 0,10 & 0,01 \\
\hline 8 & 91,00 & 11,50 & $-0,90$ & 0,81 \\
\hline 9 & 91,00 & 10,22 & $-0,90$ & 0,81 \\
\hline 10 & 90,50 & 9,15 & $-1,40$ & 1,96 \\
\hline 11 & 88,00 & 8,09 & $-3,90$ & 15,21 \\
\hline 12 & 87,00 & 7,33 & $-4,90$ & 24,01 \\
\hline 13 & 87,00 & 6,77 & $-4,90$ & 24,01 \\
\hline 14 & 86,50 & 6,25 & $-5,40$ & 29,16 \\
\hline 15 & 84,50 & 5,70 & -740 & 54,76 \\
\hline 16 & 84,00 & 5,31 & $-7,90$ & 62,14 \\
\hline 17 & 77,00 & 4,59 & $-14,90$ & 222,01 \\
\hline 18 & 77,50 & 4,36 & $-14,40$ & 207,36 \\
\hline 19 & 72,00 & 3,84 & $-19,90$ & 396,01 \\
\hline 20 & 70,50 & 3,58 & $-21,40$ & 457,96 \\
\hline$\sum$ & 1838,00 & 406,40 & & $5.909,80$ \\
\hline $\bar{x}$ & 91,90 & & & \\
\hline
\end{tabular}

Sumber : Hasil Perhitungan

Sehingga diperoleh harga:

$$
\begin{aligned}
& \bar{x}=\frac{1838}{20}=91,90 \\
& \sum(x-\bar{x})^{2}=5.909,80
\end{aligned}
$$

Dan Harga ( Yt ) dengan periode 20 tahun dapat dihitung menggunakan rumus : maka,

$$
\begin{aligned}
Y t & =-\operatorname{In}\left[\operatorname{In}\left(\frac{20}{20-1}\right)\right] \\
& =2,85 \text { (lihat tabel) }
\end{aligned}
$$

Dan Harga ( $\sigma n-1)$ dapat dihitung dengan rumus ;

Maka,

$$
\sigma n=\sqrt{\frac{5.909,80}{20-1}}=17,636
$$

Dari harga (Yn) untuk periode 20 tahun adalah 0,5236. Sedangkan dari harga ( $\mathrm{Sn}$ ) untuk periode ulang 20 tahun adalah 1,0628. Kemudian faktor $\mathrm{K}$ untuk ekstrim distribusi Gumbel dinyatakan dalam persamaan : 


$$
\begin{aligned}
& K=\frac{Y t-Y n}{S n} . \\
& \text { Maka, } K=\frac{1,052-0,5236}{1,0628}=0,49
\end{aligned}
$$

Sehingga curah hujan yang mungkin terjadi dalam periode ulang 20 tahun (x) dapat dicari dengan menggunakan rumus :

$$
\begin{aligned}
& x=\bar{x}+\sigma_{n-1} \cdot K \\
& \text { Maka, } x=91,90+(17,636 \times 0,49) \\
& =91,90+8,64 \\
& =100,54 \mathrm{~mm} \sim 100 \mathrm{~mm}
\end{aligned}
$$

Jadi Tinggi curah hujan yang mungkin terjadi dalam periode ulang 20 tahun adalah $100 \mathrm{~mm}$.

\subsection{Analisa Debit Banjir Rencana}

Metode Rasional

Dengan Metode Rasional bahwa perumusan debit maksimum dihitung dengan menggunakan rumus :

$$
Q=0,278 \text { C.I.A. }
$$

$$
\begin{aligned}
& \text { Jadi } Q_{20}=0,278 \text { C.I.A } \\
& \text { Jadi } Q_{20}=0,278 \cdot 0,75 \cdot 26,88 \cdot 29,8 \\
& \text { Jadi } Q_{20}=167,03 \mathrm{~m}^{3} / d t \sim 167 \mathrm{~m}^{3} / d t
\end{aligned}
$$

Kesimpulan dari perhitungan metode diatas, maka untuk perhitungan debit banjir rencana dalam perencanaan bangunan checkdam ini menggunakan Metode Rasional dalam periode ulang 20 tahun yaitu $167 \mathrm{~m} 3 / \mathrm{dt}$.

\subsection{Perencanaan Dimensi Checkdam}

\subsubsection{Pemilihan TypeCheckdam}

Perencanaan checkdam Kali Ngasinan, apabila ditinjau dari tebing sungai, dimana letak kedudukan Dam tersebut dapat dikatakan relatif rendah, lagi pula tebing - tebingnya merupakan tanah yang kurang dapat menjamin ujung daripada bangunan ( bila dipakai type arch ), sehingga direncanakan type gravitasi yang tinggi efektif $\leq 15$ meter.

\subsubsection{Perencanaan Dimensi Checkdam}

A. Checkdam

\section{Tampang Checkdam}

Ketebalan mercu checkdam dipengaruhi keadaan geologi dasar sungai. Mengigat pada dasar sungai banyak terdapat batu -batu besar maka tebal mercu bendung (b) diambil $=3$ meter. Keadaan pondasi menurut buku “ Volcanic Sabo Technical Center " bangunan bendung dibuat paling kecil 2 meter. Dalam kedalaman pondasi dibuat 2,5 m dibawah setiap permukaan 
tanah dasar sungai. Lebar bendung dipengaruhi oleh kemiringan muka (M1) dan kemiringan belakang (M2).

Disini :

$$
\begin{aligned}
& \text { M1 }=1: 0,20 \\
& \text { M2 }
\end{aligned}
$$

Sehingga lebar dasar Checkdam :

$$
\begin{aligned}
& =\mathrm{b}+(0,20 \times 11,50)+(0,50 \times 11,50) \\
& =3+2,30+5,75 \\
& =11,050
\end{aligned}
$$

\section{Peluap Checkdam}

Mengingat tinggi air banjir rencana $(\mathrm{h})=2,00 \mathrm{~m}$ dan tinggi dugaan $(\mathrm{dh})=$ $0,80 \mathrm{~m}$, serta kemiringan sisi peluap $1: 1$, maka lebar ambang atas mercu peluap adalah $=42,557+2(2,80)=48,157 \mathrm{~m}$.

\section{Sayap}

Sisi-sisi dari peluap checkdam merupakan sayap checkdam yang dibuat masing-masing biasanya dengan kemiringan $1: 1$ (miring ke arah apron).

4. Drip Hole (lubang drainase)

Disini dibuat 4 lubang dengan jarak antar lubang 11,00 m. Baris dibawahnya dibuat $2,50 \mathrm{~m}$ di bawah dasar lubang baris pertama, dibuat berselang dari kedudukan lubang baris pertama sejumlah 3 lubang dengan jarak antar lubang $11,00 \mathrm{~m}$.

B. Perencanaan Lantai Kolam Olah

Adapun ketebalan lantai dapat dihitung dengan rumus pendekatan sesuai dengan buku "Volcanic Sabo Technical Center" Dalam perencanaan ini :

$\mathrm{H}_{1}=10 \mathrm{~m}$

$\mathrm{h}_{3}=2 \mathrm{~m}$

Sehingga panjang lantai dapat ditentukan :

Maka :

$\mathrm{L} \quad=1,50(10+2)$

$=18,00 \mathrm{~m}$

Lebar lantai dibuat sama dengan lebar atas bendung yaitu 52,163 m. Kemiringan tembok tepi lantai minimum dapat dihitung dengan rumus:

$$
\begin{aligned}
\mathrm{Hw} & =1,50(\mathrm{~h}+\mathrm{dh}) \\
& =1,50(2,00+0,60) \\
& =3,90 \mathrm{~m}
\end{aligned}
$$




\section{Perkuatan Kaki}

Dengan posisi dasar lindungan kaki adalah 2,50 meter dari tepi ambang atas mercu checkdam. Panjang daripada perkuatan kaki sama dengan panjang apron $(18,00)$ ke hilir kolam olah. Dari hasil perhitungan checkdam bahwa :
1. Tinggi efektif checkdam $(\mathrm{H})$
$=11,50 \mathrm{~m}$
2. Tinggi bendung dari muka lantai apron $\left(\mathrm{H}_{1}\right)$
$=10,00 \mathrm{~m}$
3. Tinggi aliran diatas mercu checkdam (h)
$=2,00 \mathrm{~m}$
4. Lebar dasar mercu checkdam (b)
$=42,557 \mathrm{~m}$
5. Debit banjir yang direncanakan (Qo)
$=217 \mathrm{~m}^{3} / \mathrm{dt}$
6. Panjang lantai (L)
$=18,00 \mathrm{~m}$

\section{PENUTUP}

Berdasarkan hasil yang diteliti yang telah dilakukan didapatkan beberapa kesimpulan yaitu sebagai berikut :

A. Perhitungan Curah hujan berdasarkan Metode Log Pearson Type III pada R20 adalah sebesar $100 \mathrm{~mm}$

B. Perhitungan Debit Rencana berdasarkan Metode Rasional dalam periode ulang 20 tahun yaitu sebesar $167 \mathrm{~m}^{3} / \mathrm{dt}$.

\section{UCAPAN TERIMAKASIH}

Dalam penyusunan artikel ini, penulis ucapkan terimakasih kepada dosen pembimbing dan Universitas Kadiri. Penulis berharap agar artikel ini dapat bermanfaat bagi pembaca.

\section{DAFTAR PUSTAKA}

[1] A. Riyadi, I. Farni, and R. Rahmat, "PERENCANAAN CHECKDAM BATANG TIMBALUN KOTA PADANG," Abstr. Undergrad. Res. Fac. Civ. Plan. Eng. Bung Hatta Univ., vol. 2, no. 3, 2017.

[2] S. SUGITO, "Perencanaan Check Dam Way Rarem Di Kabupaten Lampung Utara," J. Tek. Sipil, vol. 6, no. 2, 2015.

[3] N. M. Propezite and Z. M Nur, "PERENCANAAN CHECK DAM SUNGAI PIJI KABUPATEN KUDUS,” Diss Undip, 2015.

[4] J. Sutikno, A. Ridwan, and Y. Cahyo, "ANALISA STABILITAS CHECKDAM PABYONGAN DESA MULYOSARI KECAMATAN PAGERWOJO KABUPATEN TULUNGAGUNG," Jurmateks, vol. 1, no. 1, pp. 66-75, 2018.

[5] A. C. Nugroho, H. Mudhofar, S. Sangkawati, and D. Kurniani, "Perencanaan Check Dam Galeh Kabupaten Temanggung,” J. Karya Tek. Sipil, vol. 4, no. 4, pp. 13-20, 2015.

[6] A. I. Candra, A. Yusuf, and A. R. F, "Studi Analisis Daya Dukung Pondasi Tiang Pada Pembangunan Gedung Lp3m Universitas Kadiri," CIVILLa, vol. 3, no. 2, pp. 166-171, 2018.

[7] A. E. Yulianto and S. Edhisono, "Perencanaan Check Dam Kali Gung Kabupaten 
Tegal.” Bahan Kuliah. Semarang: Jurusan Teknik Sipil Universitas Diponegoro, 2010.

[8] S. E. Wahyuni, "Hidrology Lanjut." Bahan Kuliah. Semarang: Jurusan Teknik Sipil Universitas Diponegoro, 2011.

[9] S. A. Nugroho, "Perencanaan Bendung Penahan Sedimen Kali Putih Pasca Erupsi 2010," Perenc. Bendung Penahan Sedimen Kali Putih Pasca Erupsi 2010, 2011.

[10] C. D. Soemarto, "Hidrologi teknik." Surabaya: Usaha Nasional, 1987.

[11] D. R. Maidment, Handbook of hydrology, vol. 9780070. McGraw-Hill New York, 1993.

[12] S. Qurniawati, I. Susanto, P. S. Admodjo, and S. Sangkawati, "Perencanaan Check Dam DAS Lusi Di Kabupaten Blora," J. KARYA Tek. SIPIL, vol. 3, no. 4, pp. 995-1004, 2014.

[13] S. S. Nainggolan, "Perencanaan Check Dam Penampung Sedimen Di Sungai Jepara Kecamatan Way Jepara Kabupaten Lampung Timur," 2016.

[14] R. F. Inabah, "Perencanaan Check Dam Sebagai Pengendali Sedimen Pada Sungai Yeh Mas Desa Tukad Sumaga Kecamatan Gerokgak Kabupaten Buleleng Bali," Diss UB, 2017.

[15] Q. Y. SABILA, "PERENCANAAN KONSTRUKSI BANGUNAN CHECK DAM PADA SUNGAI BATANG KURANJI SEGMEN TENGAH KOTA PADANG (STUDI KASUS CHECK DAM v BATANG KURANJI),” Diss Univ. Andalas, 2016.

[16] A. Suryanto, T. R. Putra, S. Suripin, and S. Salamun, "Perencanaan Bangunan Pengendali Sedimen Di Kali Kreo," J. KARYA Tek. SIPIL, vol. 3, no. 4, pp. 1222-1231, 2015.

[17] W. D. Wijayanto, N. Nurrahmat, A. Kadir, and P. N. Parmantoro, "Perencanaan Bangunan Pengendali Sedimen Daerah Aliran Sungai Kreo Kota Semarang," J. KARYA Tek. SIPIL, vol. 3, no. 2, pp. 427-435, 2014.

[18] S. Suhudi, "UJI STABILITAS CHECK DAM KEDUNGREJO 15 DI KALI KONTO KECAMATAN PUJON KABUPATEN MALANG," Reka Buana J. Ilm. Tek. Sipil dan Tek. Kim., vol. 1, no. 2, pp. 65-72, 2017.

[19] R. Hidayat, H. G. Putra, and K. Khadavi, "DESIGN OF CHECK DAM KURANJI RIVER PADANG CITY," Abstr. Undergrad. Res. Fac. Civ. Plan. Eng. Bung Hatta Univ., vol. 2, no. 2, 2013.

[20] I. D. Asmoro and R. Wishnumurti, "Perencanaan bangunan pengendalian sedimen sungai Gondang, Kab. Tulungagung, Jawa Timur," Diss ITS, 2014.

[21] M. A. Kuncoro, S. Winarto, and Y. Cahyo, "STUDI PENANGGULANGAN BANJIR DI KALI BATAN KABUPATEN KEDIRI,” Jurmateks, vol. 1, no. 1, pp. 91-100, 2018.

[22] A. E. Yulianto, Y. Jonatan, S. Edhisono, and A. Kadir, "Perencanaan Check Dam Kali Gung Kabupaten Tegal,” J. KARYA Tek. SIPIL, vol. 3, no. 3, pp. 638-648, 2014. 